\title{
Automated Controlling of Smart Meters
}

\author{
Chaithra Pallavi D \\ M.tech Student \\ M.S.Ramaiah Institute of Technology \\ Bangalore
}

\author{
Sumana $M$ \\ Assistant Professor \\ M.S.Ramaiah Institute of Technology \\ Bangalore
}

\begin{abstract}
Reducing the energy utilization has now become a crucial objective for many people. Transparency in the power consumption and regular feedback on energy utilization must be provided to consumers so that they can make some changes in the power consumption pattern to save energy. In this paper, we have suggested an interactive system which provides regular feedback regarding the energy utilization to the consumers. For this purpose smart electricity meters that can be remotely monitored and controlled are used. By furnishing the users with the feedback regarding the electricity usage in real-time, this system helps in identifying the biggest energy boozers and helps consumers in decreasing their energy utilization.
\end{abstract}

\section{Keywords}

AMR, AMI, GSM, GPRS, RF.

\section{INTRODUCTION}

Power sector throughout the world is undergoing a lot of changes; India is also no exception for this. The whole of the electric industry in India is in a state of flux. Power sector reforms were started in India in the face of rising commercial losses due to poor economical health of state utilities, regional capacity, energy shortages and rising subsidy load on the states. Investment in this sector could not meet the demand in the power supply. Transforming the power industry into a potent enterprise is a crucial option. The electricity industry in India is changing from organized industry to a competing industry with private players bringing in their affluent experience and huge set of resources.

Power sector re-structuring along with the Electricity Act 2003 has tiled the path for the growth of a power industry in the country. In this transformation phase, it is now crucial to model the most appropriate market suited for the country. There is significant advance in the fields of transmission and distribution, tariff rationale and in the availability of electricity supply. [1]

India has one of the rapid developing economics in the world and is graded 6th place in the universal consumer of energy. Six thousand villages occupy 72.2 percent of its human resource (census 2012). About, 40 percent of the overall energy is in rural areas, in which domestic sector comprises large-scale energy demand and its energy consumption accounts for 60 percent of energy utilized. The main sources of energy are coal and oil, while wind, nuclear and biomass are supplementary sources. Although hydropower is good potential source of energy, it is not being used to its full potential. India comprises $7 \%$ of the world's coal reserves; $0.5 \%$ of oil reserves. [2]
Following are some of the important aspects having direct and indirect effects on energy supply, to rural -

- There is a short in supply of traditional and commercial energy and the demand for the supply is increasing.

- Demand for traditional energy resources such as wood is unceasingly increasing.

- Depending on commercial fuels such as coal and oil to meet the demand results in depletion of fossil fuels and also causes environmental pollution.

- Energy supply to remote areas is linked with high transportation cost and high power transmission losses.

Thus stress should be laid on the scrutinizing of the energy in such a way that assures affordable, eco- friendly and clean energy.

That is the energy that is being utilized must be assessed and accounted for. This requires developing a stable system which collects the energy consumption data and from which all the data can be derived. This calls for developing an automated metering system that can be regulated and kept track of- wired or wireless. Hence it is important to build an architecture that consists of a main system, a set of regulated meters and a suitable communication system.

Also, electric meter reading is a tedious and an expensive task. Here the meter reader has to go to each meter and read the meter manually to generate the bill which will be later recorded in the billing software to automate the billing and payment. Automating the manual meter reading would reduce the strenuous task and financial burden on the utility company. "Automated Controlling of Smart Meters" is a system that can be used for recording the energy consumption data from the smart meter and process that data for any decision purposes.

Wireless communication is an efficient substitute for communication. One of the salient characteristics of wireless communication is that the communication is feasible without a physical network between nodes. Also, the redundant paths for communication are feasible without incurring additional cost.

\subsection{Problem Statement}

Due to continuous urbanization, shortage of fuels and growing population there is a huge need to conserve the energy in order to meet the increasing electricity demand. For this purpose the energy that is being utilized must be assessed and accounted for. Also, electric meter reading is a tedious and an 
expensive task where the meter reader has to go to each meter and read the meter manually to generate the bill. Sometimes if the meters are fixed inside people's homes and, if the user is not there at home, then it's not possible for the meter-reader to record the monthly consumption and then the utility provider has to consider the average bill-amount of the prior months as a gauge of the likely consumption of the current month. This results in obstruction for both consumer and the utility company. Hence it is important to build an architecture that consists of a main system, a set of regulated meters and a suitable communication system.

\subsection{Proposed System}

'Automated Controlling of Smart Meters' is a project that allows remote controlling and monitoring of smart meters. It eliminates the need for manually reading the meters to generate the bill and also evaluates how much energy has been utilized by the user. Also, different tariff rates can be set for peak and non peak hours so that consumer can reduce the amount of electricity usage during peak hours and can also save money on electric bill. There is also option to set and read the overload and over current threshold by sending commands to the smart meters.

\section{LITERATURE REVIEW}

Electric Energy is the driving force behind the growth of any country. With the abrupt increase in residential, commercial, and industrial consumers of electricity across the world, it has now become essential for utilities companies to design better, non-intruding, environment-friendly techniques of scaling utilities electricity usage so that correct bills can be produced and recorded. Traditionally, the electric meters are equipped on customer's premises and the consumption data is collected by meter-readers during their monthly visits to the consumer's premises

This method of appraising the electricity usage has the following drawbacks:

- Sometimes if the meters are fixed inside people's homes and, if the user is not there at home, then it's not possible for the meter-reader to record the monthly consumption and then the utility provider has to consider the average bill-amount of the prior months as a gauge of the likely consumption of the current month. This results in obstruction for both consumer and the utility company. There is a possibility that the consumer has not used similar amount of electricity in the current month compared to the previous months due to some reasons such as, enjoying vacations elsewhere or being treated in the hospital, etc. during that month, and sending him a bill for a greater amount formed on his history of electricity usage may result in his/her financial labor. This method of estimating the bills is also not suitable for the utility company because it gives inaccuracy in the consumer's bills and may finally result in fallacies in future planning by the utility company.

- Hiring a number of meter readers for billing and providing means of transportation for their monthly visits to the consumers premises is an expensive load on the company's budgets.

There is a possibility that the meter readers may do some errors while reading the consumed unit which will result in false billing due to human mistake. [3]
In order to overcome these drawbacks a new meter reading system 'Automatic Meter Reading (AMR)' was developed that automates the meter reading task. That is, it collects the energy utilization data automatically and transfers that data to the utility providers. [4]

Currently many AMR systems are implemented using GPRS, Bluetooth and Global System for Mobile communication (GSM) technology. GPRS is mainly used for long distance transmission of data but it is not possible to implement, since regular use of GPRS is difficult for common people. Using GSM technology remote billing is possible but there is a possibility of missing SMS which will decrease the performance of the system. [5]

In "Automated EB Billing System Using GSM and Ad-Hoc Wireless Routing" there is a central office that has remote access to all the electric meters of the consumer using Radio Frequency (RF) system. The electric meter in each home is connected via wireless system with the office which gets regular updates from the electric meter. Then, according to the number of units consumed amount to be paid is calculated. [6]

In "Prepaid Energy Meter based on AVR Microcontroller" prepaid feature has been introduced and AVR controller has been used as it is consumes less energy. These meters are cheaper since only a small modification has been made on existing traditional meters which change them to prepaid meters. [7]

The paper "Design and Development of GSM based Energy Meter" presents design and implementation of AMR system. This system provides power consumption data, total load used to the utilities with the help of GSM. [8]

Here, there is no option for prepaid recharging, changing tariff rates, and changing threshold values. 'Automated Controlling of Smart Meters' is a system that allows us to set and read tariff rates, threshold values by sending commands to the smart meters remotely.

\section{PROPOSED TECHNOLOGY}

Smart Meters are advanced sophisticated meters that collect the energy utilization data more accurate than the traditional electric meters and communicate that information back to the utility providers for monitoring, controlling and billing purposes.

\section{Smart Meter are the ones that}

- Collects and stores the energy consumption data at regular intervals

- Allows for two way communication between the utility provider and user.

This brings a breakthrough in customer-utility relationship, which allows for remote connection and disconnection, remotely changing the tariff, setting peak and non peak hours, remotely measuring the overload and over current threshold. Automated Meter Reading (AMR) meters only gather energy utilization data from the smart meters. These meters are used by commercial customers and industries to measure their energy utilization for hourly or half hourly intervals. They assure correct billing, ease in supplier switching and helps in encountering the defects easily compared to the traditional meters. 
'Automated Controlling of Smart Meters' attributes to network of meters and their associated communications. It provides accurate details regarding the energy utilization and upgraded data flows to facilitate demand response - managing the demand in response to the current energy supply provisions. The communication networks are designed so that they can be used to remotely control the electrical accompaniments, in order to achieve optimization in the system operation and in the usage of sporadic energy supply. It also allows for anticipation of the advanced metering and collecting of energy utilization data and on-site generation. It is also designed to realize the load control during high resolution (i.e. remotely monitoring the individual electrical appliances for each second) in order to handle the inconstancies in the demand and power supply. This becomes necessary as many intermittent renewable energy generations are in line.

A Smart Meter consists of three components:

- Electrical Meter: It measures the energy utilization at the power line and converts those readings into data that can be interpreted by the processing unit for monitoring purposes.

- Processing Unit: Its function is to process and record the data received from the meter in order to control and monitor the meter and communication unit.

- Communication Module: It can be implanted within the smart meter or in an extension slot, That is, different communication modules can be used with the same meter based on different circumstances.

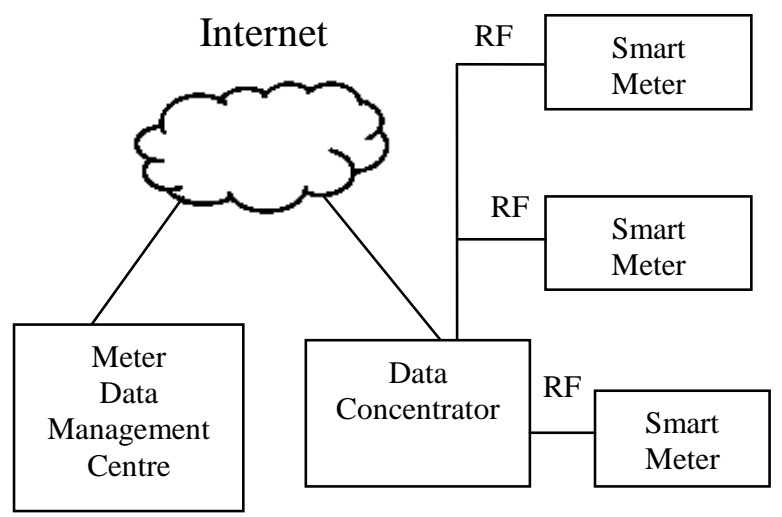

Figure 1: Communication model

Smart Meters transmit the data through low module RF to the data concentrators to accumulate the data and then send it to the central meter data management system as shown in the Figure 1 . The electrical meter is highly controlled and has to satisfy a set of national standards. Also, Relay ON/OFF switch functionality is provided in the smart meter. That is, the power will be automatically disconnected from the users who have not made their payments or recharged on time.

Real time recording and reporting of energy utilization allows for improved management of energy distribution by lessening the power loss and sustain the competence of the energy production. Smart meters record and transmit the consumption data at regular intervals which can be changed to real time recording and reporting eventually. We can also retrieve information regarding current load and which meters are currently connected by simply sending commands to the smart meter. Also, some customers may implant other energy production systems such as solar panels. In such cases smart meter keeps track of the extra energy produced.

In order to control the smart meters remotely commands such as change and read tariff, change and read the overload threshold, recharge, read currency are developed and sent to the smart meters.

\section{ADVANTAGES OF SMART METERING}

Avoidance of manually reading meters as in the case of traditional meters is one of the significant benefits which are possible through remote reading of meters. Any disruption in the service can be detected easily resulting in faster response times, real time recording of consumption data and accurate billing improves the competence of metering services. This results in low number of customer complaints which is an advantage for the utility providers. Also, different rates will be fixed for peak hours and non peak hours so that customer can shift the electricity usage from peak to non peak hours which help in conserving the energy. [9]

\section{CONCLUSIONS AND FUTURE SCOPE}

In this paper we proposed a system which records the energy utilized by the consumers and transmits that information to the utilities for monitoring, controlling, billing and other purposes. There is no need for manually reading the meters as in case of traditional meters and all the operations on the smart meters can be carried out by sending the commands remotely. Also different tariff rates for peak and non peak hours can be set so that energy can be conserved during peak hours and it also helps in reducing the bill of the customer. By providing real time energy utilization feedback to the consumers the smart metering system serves to reduce the power consumption and conserve energy.

Future enhancement to the project can be done by triggering the usRrsdpy Fendieg the mail or message regarding the energy usage and remaining prepaid balance.

\section{REFERENCES}

[1] BadiquFrequqdey Sidappa Naidu2, "Design and Implementation of Automatic Meter Reading System Using GSM, ZIGBEE through GPRS”, International Ratidinalequefidvanced Research in Computer Science and Software Engineering Volume 2, Issue 5, May 2012 ISSN: 2277 128X.

[2] Tanvir ahmed1, MD Suzan miah2, MD. Manirul islam3 and MD. Rakib uddin, "Alternative approach in meter reading for Bangladesh perspective using low-cost digital wattmeter and wimax technology", International J. Eng. Tech 8(3):800-807, September 2011.

[3] Smart Meters and Smart Meter Systems: A Metering Industry Perspective, an EEI-AEIC-UTC White Paper.

[4] Chunjuan WEI, Junjie YANG, "Implementation of Automatic Meter Reading System Using PLC and GPRS", Journal of Information \& Computational Science 8: 16 (2011) 4343-4350. 
[5] Shraddha Male et al "A Smart Wireless Electronic Energy Meter Reading Using Embedded Technology", International Journal of Engineering Research and Application, ISSN : 2248-9622, Vol. 4, Issue 1 (Version 3), January 2014, pp.145-147

[6] Vijayaraj et al [1] "Automated EB Billing System using GSM and Ad-Hoc Wireless Routing", International Journal of Engineering and Technology Vol.2 (5), 2010, 343-347.

[7] IrfanQuazi et al [2], "Pre-paid Energy Meter based on AVR Microcontroller", International Journal of
Engineering Research and Applications (IJERA) ISSN: 2248-9622www.ijera.com Vol.1, Issue 4, pp.1879-1884.

[8] Abhinandan Jain, "Design and Development of GSM based Energy Meter", International Journal of Computer Applications (0975 - 888) Volume 47- No.12, June 2012.

[9] Aoife Brophy Haney, Tooraj Jamasb and Michael, G. Pollitt, "Smart Metering and Electricity Demand: Technology, Economics and International Experience", EPRG Working Paper EPRG0903 Cambridge Working Paper in Economics 0905. 